\title{
Mitogenomics of the Old World monkey tribe Papionini
}

\author{
Rasmus Liedigk ${ }^{1 *}$, Christian Roos ${ }^{1,2}$, Markus Brameier $^{1}$ and Dietmar Zinner ${ }^{3}$
}

\begin{abstract}
Background: The evolutionary history of the Old World monkey tribe Papionini comprising the genera Macaca, Mandrillus, Cercocebus, Lophocebus, Theropithecus, Rungwecebus and Papio is still matter of debate. Although the African Papionini (subtribe Papionina) are generally considered to be the sister lineage to the Asian Papionini (subtribe Macacina), previous studies based on morphological data, nuclear or mitochondrial sequences have shown contradictory phylogenetic relationships among and within both subtribes. To further elucidate the phylogenetic relationships among papionins and to estimate divergence ages we generated mitochondrial genome data and combined them with previously published sequences.

Results: Our mitochondrial gene tree comprises 33 papionins representing all genera of the tribe except Rungwecebus. In contrast to most previous studies, the obtained phylogeny suggests a division of the Papionini into three main mitochondrial clades with similar ages: 1) Papio, Theropithecus, Lophocebus; 2) Mandrillus, Cercocebus; and 3) Macaca; the Mandrillus + Cercocebus clade appears to be more closely related to Macaca than to the other African Papionini. Further, we find paraphyletic relationships within the Mandrillus + Cercocebus clade as well as in Papio. Relationships among Theropithecus, Lophocebus and Papio remain unresolved. Divergence ages reveal initial splits within the three mitochondrial clades around the Miocene/Pliocene boundary and differentiation of Macaca species groups occurred on a similar time scale as those found between genera of the subtribe Papionina.

Conclusion: Due to the largely well-resolved mitochondrial phylogeny, our study provides new insights into the evolutionary history of the Papionini. Results show some contradictory relationships in comparison to previous analyses, notably the paraphyly within the Cercocebus + Mandrillus clade and three instead of only two major mitochondrial clades. Divergence ages among species groups of macaques are similar to those among African Papionini genera, suggesting that diversification of the mitochondrial genome is of a similar magnitude in both subtribes. However, since our mitochondrial tree represents just a single gene tree that most likely does not reflect the true species tree, extensive nuclear sequence data is required to illuminate the true species phylogeny of papionins and to trace possible ancient hybridization events among lineages.
\end{abstract}

Keywords: Phylogeny, Divergence ages, mtDNA, Primates, Macaques, Baboons

\section{Background}

It is well recognized that mitochondrial (mtDNA) phylogenies are not necessarily congruent with the phylogeny of the respective taxa or phylogenies based on a set of nuclear genes (e.g. [1-3]). Reasons for the incongruence are manifold, e.g., different inheritance pathways, divergent selection pressures, and most prominent, incomplete lineage sorting and horizontal gene flow (e.g. [4,5]). On

\footnotetext{
*Correspondence: rliedigk@gmx.de

${ }^{1}$ Primate Genetics Laboratory, German Primate Center, Leibniz Institute for Primate Research, Kellnerweg 4, 37077 Göttingen, Germany

Full list of author information is available at the end of the article
}

the other hand, if mtDNA and nuclear (nDNA) phylogenies are congruent this could be a strong indication that the single underlying gene tree is congruent with the species tree. Furthermore, in many species analyses of mtDNA relationships provide a better spatial resolution, thus contributing to phylogeographical inferences $[3,6]$. Therefore, analyses of both, mtDNA and nDNA, are necessary for a comprehensive understanding of the evolutionary history of taxa and for a robust reconstruction of complex phylogenies.

Among primates, incongruences are reported for several taxa within the Old World monkey tribe Papionini 
(e.g. [7-14]). The Papionini tribe diverged from its sister lineage, the Cercopithecini, around 11.5 million years ago (Ma) [15] and comprises the subtribe Papionina, with the genera Papio, Mandrillus, Theropithecus, Cercocebus, Rungwecebus and Lophocebus, and the subtribe Macacina, with the genus Macaca [16]. While all available nDNA data and respective gene trees are congruent and strongly support this division $[15,17,18]$, recent studies applying mtDNA genome data suggest the Mandrillus + Cercocebus clade to be closer related to Macaca [19,20], thus indicating paraphyly of Papionina in the mtDNA gene tree.

The African origin of the tribe is broadly accepted [16,21-25] and the fossil record indicates a Late Miocene dispersal out of Africa into Eurasia for some lineages. Remains of macaques have been found in southern, western and central Europe [26,27], whereas fossil macaques from Asia are documented but rather scarce [26]. Fossils of Theropithecus have been recovered from the Iberian Peninsula as well as from India [28-34]. Today the six genera of Papionina are found exclusively on the African continent, with the exception of the hamadryas baboon, which occurs in both northeastern Africa and the southwestern Arabian Peninsula [16,25]. In contrast, members of the subtribe Macacina are distributed over large regions of South, Southeast and East Asia with the exception of Barbary macaques, which are found in Northwest Africa. Based on morphological characters, the subtribe Papionina is divided into six relatively heterogeneous genera, while the Asian lineage consists of only one highly speciose genus (Macaca), which is divided into several species groups [16,23,26,35].

The tribe comprises 45 species [36], exhibiting a great variety of morphologies from more slender representatives like the crested mangabeys to more robust forms like baboons, mandrills and drills. The genus Macaca is divided into species groups, but the number and the composition of these species groups have been a matter of debate for decades $[23,26,35]$. Based on the morphology of male genitals Fooden [35] proposed four species groups comprising a $M$. silenus-M. sylvanus, a $M$. fascicularis, a $M$. arctoides and a M. sinica group, with a total of 19 species. Delson [26] also proposed four species groups but moved $M$. arctoides into the $M$. sinica group and separated $M$. sylvanus from the $M$. silenus lineage into its own group. Combining morphological and genetic data, Groves [23] proposed a classification into six species groups with a total of 20 species: (1) the monotypic $M$. sylvanus group, (2) the M. nemestrina group, (3) the Sulawesi group, (4) the $M$. fascicularis group, (5) the M. mulatta group and (6) the $M$. sinica group. In the most recent classification the genus Macaca consists of 22 species, in seven species groups [16], among them three monotypic species groups: (1) M. sylvanus group, (2) M. arctoides group and (3) M. fascicularis group, and four polytypic groups:
(4) Sulawesi group, (5) M. mulatta group, (6) M. sinica group and (7) M. silenus group. Although the monophyly of the macaques was confirmed in several studies $[23,26,35,37,38]$, relationships among and within the species groups are still disputed [37-40].

Similarly, within the African Papionina, relationships among genera and species are only partly resolved [41]. Findings based on morphological traits were often discordant with results from molecular studies. While early morphological analyses supported the monophyly of the mangabeys [42,43], more recent morphological [44-46] and molecular studies $[17,47,48]$ suggested diphyly of mangabeys, with Lophocebus clustering with Papio and Theropithecus, while Cercocebus forms a clade with Mandrillus. The kipunji (Rungwecebus kipunji), earlier described as a member of Lophocebus [49], was recently placed in its own genus [50]. Subsequent genetic studies confirmed the diphyly of Lophocebus and Cercocebus, and in addition showed a close relationship of Rungwecebus to Papio [10,50,51]. Concerning Papio, genetic analyses revealed seven well-supported mtDNA haplogroups, but these were not congruent with the six recognized species of the genus [11,42,52-54]. Likewise, for the Mandrillus + Cercocebus clade a mtDNA study indicated paraphyly of Cercocebus with at least one species (C. torquatus) being more closely related to Mandrillus than to its congenerics [12], while nuclear gene trees suggest reciprocal monophyly of both genera $[14,15]$. Previous morphological studies noted some similarities between Mandrillus, Cercocebus and Macaca. Fleagle and McGraw [45,55] studied postcranial features of Mandrillus, Cercocebus, Lophocebus and Papio and compared them with respective data of one macaque species (M. nemestrina). Most characters of Mandrillus and Cercocebus did not differ from those of $M$. nemestrina, and were therefore interpreted to be primitive among papionins, whereas just one of the investigated traits in $M$. nemestrina did not differ from that of Lophocebus, Papio and Theropithecus $[45,55]$. Furthermore, although it is widely accepted that Lophocebus and Theropithecus cluster together with a clade consisting of Papio and Rungwecebus, the branching pattern among these lineages is unresolved $[14,19,20,56]$.

It has recently been shown that the use of complete mtDNA genome sequences provide better statistical support in phylogenetic reconstructions when compared to analyses based on single genes or partial genomes (e.g. [57-60]). In our study we generated new mtDNA genome data of Macaca species and combined it with respective data of other Papionini from GenBank to reconstruct a robust mtDNA gene tree of papionin primates and to estimate respective divergence ages. We were particularly interested to obtain further information concerning the branching pattern among papionin genera and among all seven species groups of the genus Macaca and to 
provide comprehensive data for further comparative molecular studies.

\section{Results}

We sequenced complete mtDNA genomes from eight macaques representing all seven macaque species groups: M. sylvanus - M. sylvanus group, M. silenus - M. silenus group, $M$. tonkeana - Sulawesi group, $M$. thibetana $-M$. sinica group, M. mulatta/China and M. mulatta/India M. mulatta group, M. fascicularis/Vietnam - M. fascicularis group, and $M$. arctoides - $M$. arctoides group. A BLAST-search in GenBank showed that our newly generated sequences matched almost perfectly with available orthologs. The full-length genome sequences consisted of 13 protein-coding genes, 2 rRNA genes, 22 tRNA genes and the control region. The initial alignment comprised
38 sequences and had a length of 16,966 base pairs (bp). After indels and poorly aligned positions were removed the alignment comprised 15,685 bp including 6,986 informative sites. The alignment is available for download (Additional file 1 [61]).

The phylogenies as obtained from maximum-likelihood (ML) and Bayesian analyses are mainly identical and most branching patterns are strongly supported (Figure 1). Likewise, the Densitree [62] depicting the posterior distribution of the 25,000 trees as inferred from the Bayesian divergence age analysis in BEAST suggests the most frequent tree topology to be identical to that obtained from ML and Bayesian analyses (Figure 2). According to divergence age estimations using autocorrelated and uncorrelated clock models, the Old World monkeys (Cercopithecoidea) diverged from the Hominoidea between 24 and $27 \mathrm{Ma}$ (for

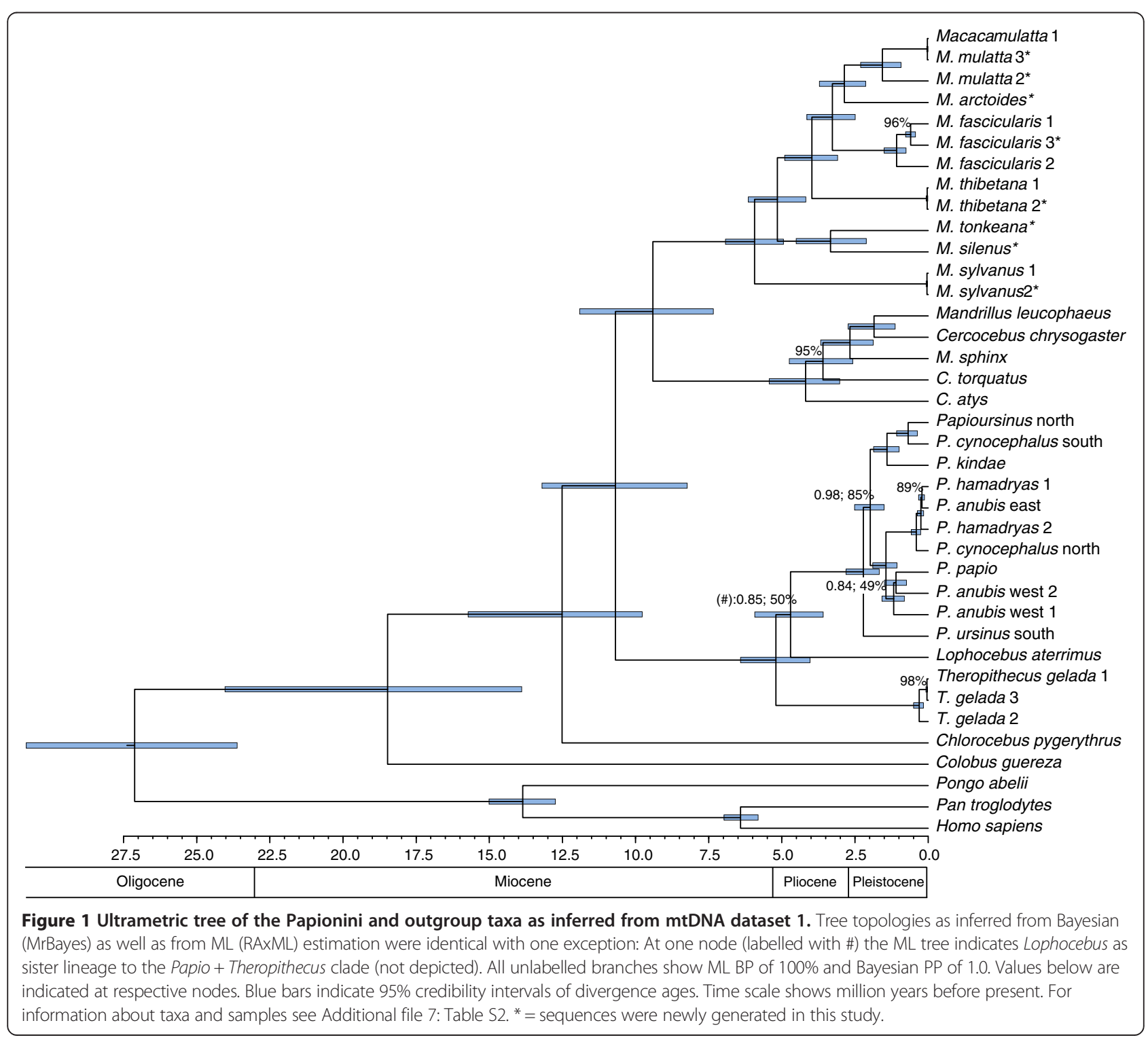




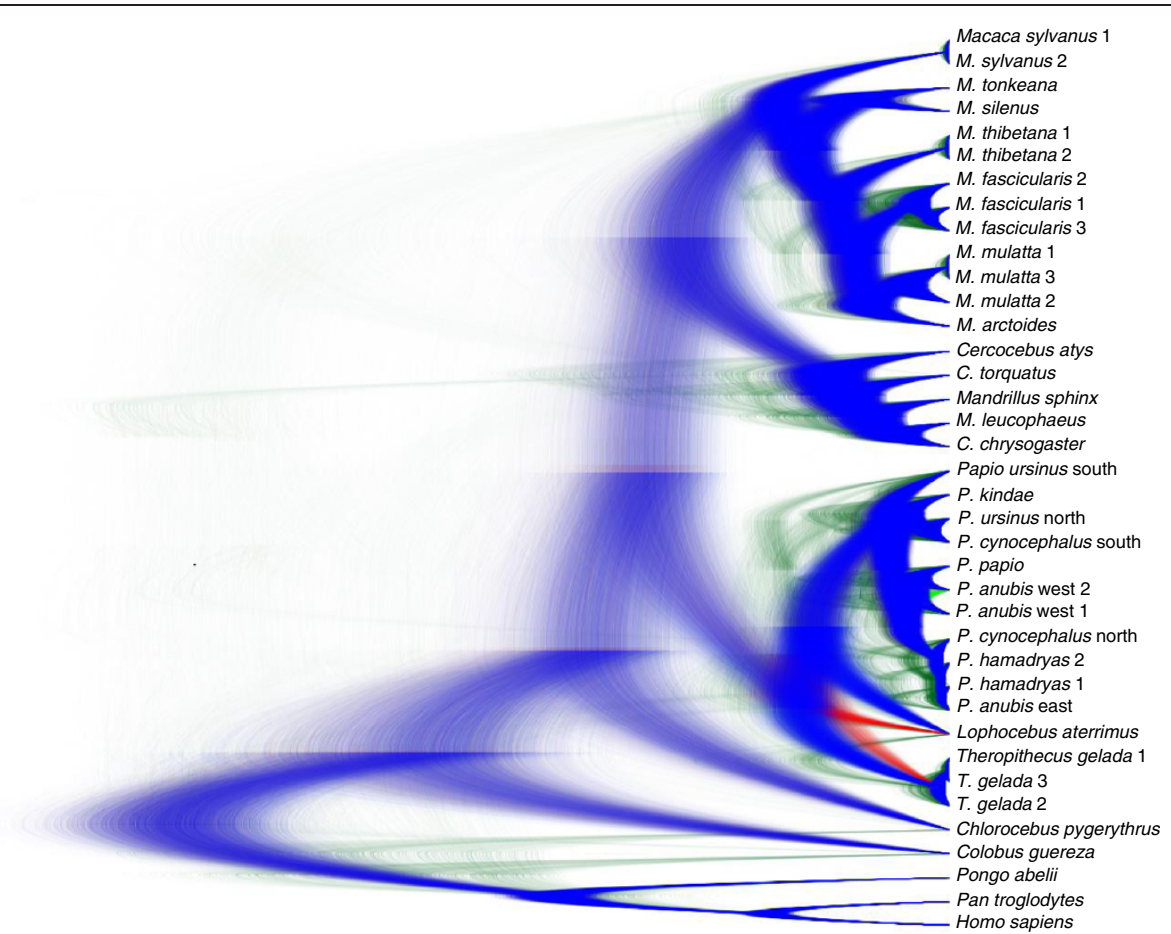

Figure 2 Densitree showing the posterior probability of 25,000 trees taken from the Bayesian divergence age analysis in BEAST. Blue represents the most frequent tree topology, red represents the second and green the third most frequent topology.

95\% credibility intervals see Additional file 2: Table S1). In the Early Miocene, the two subfamilies of the Cercopithecidae, Colobinae and Cercopithecinae, separated, and the latter subfamily further split into Cercopithecini and Papionini between 11 and $16 \mathrm{Ma}$. Our analysis revealed three major clades within the Papionini which diverged 9$13 \mathrm{Ma}$. Interestingly, the Mandrillus + Cercocebus clade forms a sister lineage to Macaca (ML bootstrap value [BP]: 100\%; Bayesian posterior probability [PP]: 1.0) and does not cluster with the second major African papionin clade comprising Papio, Lophocebus and Theropithecus (BP: 100\%; PP: 1.0). Since Mandrillus and Cercocebus show a shift in $\mathrm{A} / \mathrm{C}$ content similar to macaques (Additional file 3: Figure S1), which could lead to an artificial clustering [63], we repeated our analysis with a modified dataset (dataset 2) that corrects for this shift. Accordingly in this second alignment we masked positions that contain both an Adenin and Cytosin with an "M". The resulting overall branching pattern and specifically the phylogenetic position of the Mandrillus + Cercocebus clade among papionins were identical to those obtained from the original dataset (Additional file 4: Figure S2). To further test for alternative positions of the Mandrillus + Cercocebus clade among papionins, we performed alternative tree topology tests, which revealed that all alternative options are statistically rejected (Figure 3 ).

Within the Mandrillus + Cercocebus clade, members of both genera do not form reciprocally monophyletic clades.
In dataset $1 C$. atys is the first lineage to split off (4.2-4.9 Ma) followed by C. torquatus (3.6-4.3 Ma), while M. sphinx represents a sister lineage to $C$. chrysogaster and M. leucophaeus (BP: 100\%; PP: 1.0) which separated from them 2.7-3.4 Ma. The latter two diverged 1.92.6 Ma. The Bayesian analysis of dataset 2 shows the same topology, but partly with low support (PP: 0.56) while the ML analysis of dataset 2 suggests a possible clade consisting of C. atys and C. torquatus which, however, is only weakly supported (BP: 49\%) (Additional file 4: Figure S2).

Within the second African papionin clade, the branching pattern among the three genera Papio, Theropithecus and Lophocebus is not well resolved. While in the Bayesian analysis of the original dataset, Theropithecus is suggested as the first lineage to diverge (PP: 0.85), ML analysis of dataset 1, as well as ML and Bayesian analyses of dataset 2 indicates a Theropithecus + Papio clade to the exclusion of Lophocebus. Node supports for respective branching patterns are low (dataset 1, BP: 50\%; dataset 2, PP: 0.89; BP: 83\%). Similarly, the Densitree indicates Lophocebus + Papio as the most frequent clade, while the second most frequent clade is formed by Theropithecus and Papio. Estimated divergence ages suggest that respective splitting events occurred during a short time period around 5 Ma. Among Papio representatives the tree topology is identical and divergence ages are similar as previously reported [54], depicting paraphyletic relationships in P. ursinus, $P$. cynocephalus and $P$. hamadryas, and polyphyletic 


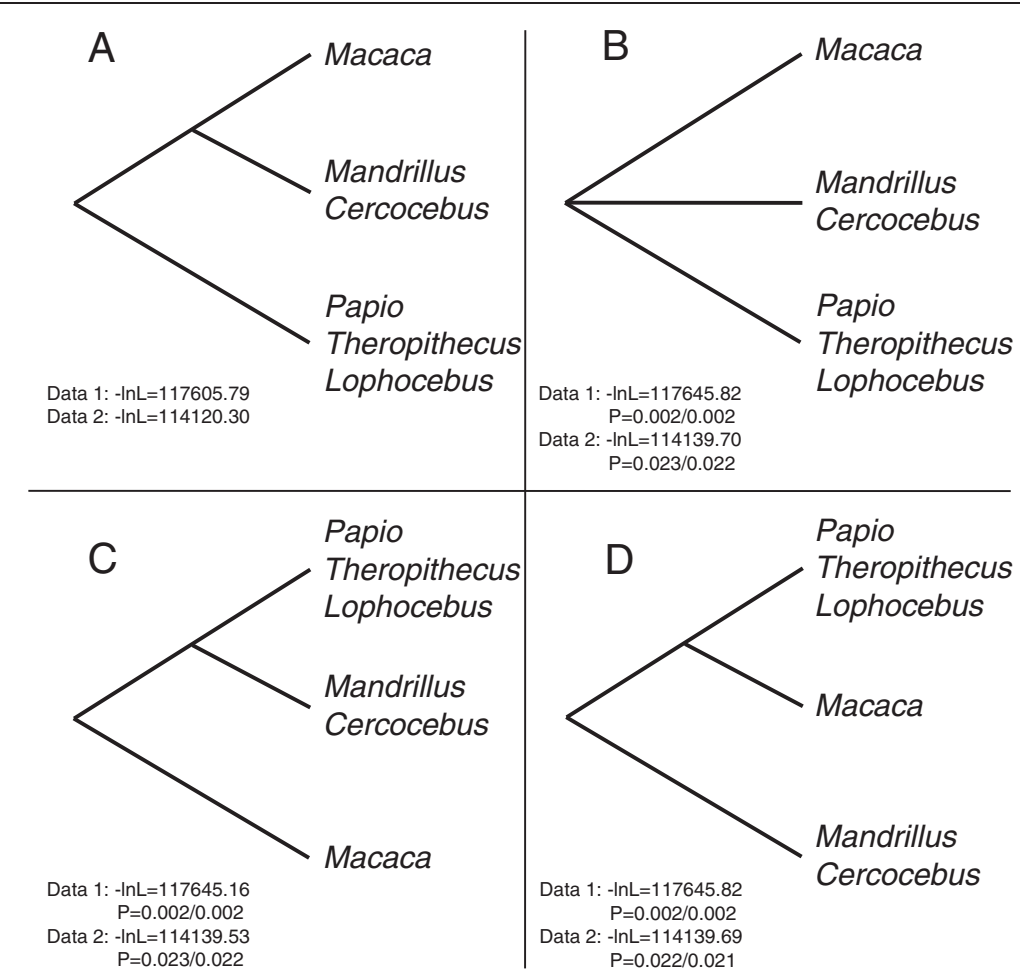

Figure 3 Tree topologies that were tested in the alternative tree topology test. Tree $\mathbf{A}$ represents the most probable topology, whereas B, C and D were significantly rejected. Log-likelihood and P values for each tree topology are given for dataset 1 and 2, respectively. First and second $\mathrm{P}$ values resulted from the Kishino-Hasegawa and the Shimodaira-Hasegawa tests, respectively.

relationships in P. anubis. According to estimated divergence ages, splitting events within Papio started around $2 \mathrm{Ma}$.

Among macaques, Macaca sylvanus diverged first, 5.9-6.3 Ma. Subsequently the Asian macaques radiated and successively split into the six Asian species groups. The $M$. silenus $+M$. tonkeana ( $M$. tonkeana as representative of the Sulawesi group) clade separated from the remaining macaques between 5.2-5.9 Ma and further segregated into two species groups $(3.2-4.6 \mathrm{Ma})$. Among the remaining macaques, $M$. thibetana (as representative of the $M$. sinica group) diverged between 3.9-5.0 Ma from a $M$. fascicularis $+M$. arctoides $+M$. mulatta clade. Within the latter, $M$. fascicularis split off first (3.2-4.6 Ma) whereas $M$. arctoides separated from the $M$. mulatta clade slightly later (2.7-4.3 Ma). Within M. fascicluaris and M. mulatta we found relatively ancient splitting events of 1.1-2.2 Ma and 1.4-2.9 Ma.

\section{Discussion}

The application of complete mtDNA genome sequences revealed highly supported branching patterns for most of the investigated papionin lineages. The mtDNA gene tree as well as estimated divergence ages are broadly consistent with those reported in previous studies, but also show some remarkable, but not unexpected discordances to recent nDNA studies $[15,19,20,54,64,65]$.

The major findings of our analysis are: 1) a sister grouping of Macaca and the Mandrillus + Cercocebus clade, 2) paraphyly within the Mandrillus + Cercocebus clade, 3) unresolved relationships among Papio, Lophocebus and Theropithecus, and 4) similar divergence ages among Macaca species groups and papioninan genera. Furthermore, our phylogenetic reconstruction reveals highly supported branching patterns among the seven Macaca species groups, which are largely in agreement with most previous studies (e.g. $[15,37,66])$. The only exception is the phylogenetic position of $M$. arctoides, which is here strongly supported as the sister lineage to the $M$. mulatta group. This finding is not surprising given the evidence that $M$. arctoides is the result of hybridization between ancestral forms of the M. sinica and M. mulatta groups $[37,66]$.

Divergence dates are mostly consistent regardless of the software (BEAST or PhyloBayes) and clock model (autocorrelated or uncorrelated) that were applied (Additional file 2: Table S1, Additional file 5: Figure S3, Additional file 6: Figure S4). Our estimation indicates a separation of African and Asian macaques around $6 \mathrm{Ma}$ which is in line with Alba et al. [27], who, based on fossil data, proposed a macaque dispersal from Africa into Eurasia by the Late 
Miocene (5.3-5.9 Ma). Generally, our divergence age estimations reveal a stepwise but rapid radiation of macaque species groups between 5.9 and $2.7 \mathrm{Ma}$ in Asia, which is in agreement with the appearance of the earliest Macaca-like fossil in Asia which was found in the Yushe Basin (China) from about $4 \mathrm{Ma}$ [27]. At that time two of the six main lineages of Asian macaques were already established as indicated by our divergence age estimations. To further test possible dispersal scenarios in Southeast Asia and especially in Sundaland additional taxa of the species groups from different locations have to be included in future analyses.

We found the Mandrillus + Cercocebus clade to be more closely related to the macaques than to other African Papionina, a pattern also reported by Finstermeier et al. [19] and Pozzi et al. [20]. However, in contrast to Finstermeier et al. [19] alternative tree topology tests with our data were clearly rejected (Figure 3), which most likely can be explained by the increased taxon sampling in our study (33 sequences this study, 11 sequences in Finstermeier et al. [19]), because it is known to reduce phylogenetic error [67-70]. Moreover, since we controlled for the observed shift in A/C content, the Mandrillus + Cercocebus clade might be indeed more closely related to Macaca than to the other African papionins, at least if we consider mtDNA. This finding, however, is contradictory to relationships based on recent nuclear studies, which found the Macacina and Papionina to be reciprocally monophyletic $[15,18]$. Perelman et al. [15] found this branching pattern in a concatenated dataset of 54 nDNA loci (BP: 100\%) as well as in six separately analysed subsets, of which four are similarly highly supported (BP: 97-100\%). Likewise, the presence/absence pattern of Alu integrations revealed no conflicting integrations, suggesting reciprocal monophyly of both clades [18] and Springer et al. [71], analysing a combined dataset of mtDNA and nDNA sequences, found the same pattern. Interestingly, comparative morphological studies investigating postcranial traits of African Papionina (Mandrillus, Cercocebus, Lophocebus and Papio) and one species of Macaca (M. nemestrina) suggest some similarities between Mandrillus + Cercocebus and the macaque [45,55]. However, since only one macaque species was included in the analysis, results concerning the relationship of Mandrillus + Cercocebus to Macaca have to be considered with caution. The question is whether the similarities between Mandrillus, Cercocebus and M. nemestrina are due to the plesiomorphy of the traits as suggested by Fleagle \& McGraw [45,55] or whether they result from convergent adaptations to similar ecological niches since Mandrillus, Cercocebus and $M$. nemestrina are predominantly forest dwelling terrestrial primates [72,73]. Given that nDNA phylogenies (e.g. [15]) may reflect the true species relationships more reliably than mtDNA phylogenies with Macaca being basal to the Papionina, we would assume that morphological similarities result from convergent adaptation. In contrast, the present mtDNA phylogeny would rather accord to the assumption that the shared morphological features are primitive.

Inconsistencies of mitochondrial and nuclear phylogenies are often explained by incomplete lineage sorting or ancient hybridization $[5,19,37,59,60,74,75]$. At the moment, we cannot determine if one or both phenomena affected the suggested phylogenetic relationships. A possible scenario based on hybridization could be that ancestral representatives of the Mandrillus + Cercocebus clade were indeed more closely related to ancestral macaques, but were later introgressed by an ancestor of the Papio + Theropithecus + Lophocebus clade, resulting in nuclear swamping. Hybridization seems to be common among extant papioninan taxa, even between genera $[11,12,76,77]$. It is therefore likely that hybridization and introgression also occurred among the ancestral papioninan lineages which lead to the observed incongruence between nDNA and mtDNA phylogenies. However, as mentioned above, incomplete sorting of mitochondrial lineages in these taxa is also a plausible explanation for the observed relationships.

Our mtDNA genome tree revealed paraphyletic relationships of Mandrillus and Cercocebus taxa, which is again contradictory to nDNA studies that suggest both genera to be reciprocally monophyletic $[14,15]$. As our data show, $M$. leucophaeus clusters with $C$. chrysogaster and M. sphinx is indicated as sister lineage to both to the exclusion of $C$. torquatus and $C$. atys. Again, ancient hybridization and incomplete lineage sorting cannot be excluded as having affected this branching pattern. However, since the species identification of the herein used $C$. torquatus sample is questionable (originally identified as Lophocebus albigena [78]), our results have to be regarded as preliminary and at the moment any further discussion of possible phylogeographic scenarios would remain highly speculative. Interestingly, however, the sister relationship of C. chrysogaster to M. leucophaeus is consistent with Kingdon's [79] p.46 observation that C. chrysogaster is morphologically "the most drill-like of the drillmangabeys". On the other hand, Kingdon's suggestion has not been held up by several other studies, which find $C$. torquatus to be the most primitive and Mandrillus-like mangabey [14,45,46,55,72]. Comprehensive sampling of mangabeys with reliable information on their geographic provenance is required to further elucidate relationships within the Mandrillus + Cercocebus clade.

Relationships among Papio, Theropithecus and Lophocebus have been analysed in several studies, but differed depending on the markers that were applied. Chatterjee at al. [56] investigated seven mitochondrial genes and found Theropithecus clustering with Lophocebus to the exclusion of Papio while Finstermeier et al. [19] showed 
a closer, but only weakly supported mtDNA genome affiliation of Papio to Theropithecus; Pozzi et al. [20] were also not able to resolve these relationships. Likewise, while we found Theropithecus split off first in the Bayesian analysis of the original dataset, ML analysis as well as both, Bayesian and ML estimations of dataset 2 suggested Lophocebus in the basal position. For both datasets, support values for respective branching patterns are low and estimated divergence ages among the three genera indicate a rapid radiation around $5 \mathrm{Ma}$. Also in the Densitree, different branching patterns are depicted. Accordingly, the present data are probably not sufficient to resolve the branching pattern. On the other hand, nDNA sequence data revealed a more consistent picture by placing Lophocebus with Papio to the exclusion of Theropithecus $[14,15,48,56,71]$. Not surprisingly, morphological (i.e., craniodental) data are congruent with these molecular studies when allometry is properly accounted [80,81]. Guevara \& Steiper [14] stated that the basal position of Theropithecus is plausible given that known fossils [82] of the genus are considerably older ( 4.0 Ma) than those of Papio ( 2.5 Ma) and Lophocebus ( 2.0 Ma). It has been shown that an increased sampling of more individuals per species may help to resolve phylogenies with short internodes, but nevertheless an increased sampling will not improve the phylogenies when hybridisation has confounded it $[14,74]$.

The initial radiation within the Papionini into the three main lineages 1) Papio, Theropithecus and Lophocebus, 2) Mandrillus and Cercocebus, and 3) Macaca took place during the Late Miocene. Within these three clades, further differentiation events occurred on similar time scales (Theropithecus - Lophocebus - Papio: 5-6 Ma; Mandrillus - Cercocebus: 4-5 Ma; Macaca: 5-6 Ma). (Figure 1, Additional file 2: Table S1, Additional file 4: Figure S2). This means that, although macaques seem morphologically not as diverse as their African sister taxa $[23,35,83]$, the mitochondrial heterogeneity among species groups is at least as high as among the African papionin genera. Comparing our mtDNA divergence ages with those inferred from nDNA data (e.g. [15]) we find that those splits slightly differ but tend to be in the same range (Additional file 2: Table S1). We therefore can assume nuclear heterogeneity among Macaca species groups and Papionina genera to be also in a similar range.

Given the equally long independent evolutionary histories of macaque species groups and Papionina genera the question of whether the species groups represent rather distinct genera or whether the two main African Papionina clades constitute only two genera (Papio and Cercocebus) with diverse species groups seems a subject for debate. However, due to morphological similarities of the macaque taxa and the morphological differences between the African genera, a reorganisation of their taxonomic ranks based on time depths as proposed by Goodman [84] and Groves $[23,85]$ seems not to be justified at the moment.

\section{Conclusion}

By analysing complete mtDNA genomes of all papionin genera (with the exception of Rungwecebus) we obtained well-resolved phylogenetic relationships and higher support values than inferred from shorter mtDNA fragments. Our estimated divergence ages are similar to those of other studies but credibility intervals are narrowed down due to the application of complete mtDNA genome sequences. Including an increased number of papionin samples led to a different tree topology concerning the phylogenetic position of the Mandrillus + Cercocebus clade among papionins, which is in stark contrast to previous $\mathrm{nDNA}$ studies, indicating that ancient introgression or incomplete lineage sorting may have played a role here. However, which of the two processes led to these contradictions cannot be determined here since we analysed only the maternal lineage of included taxa.

Although the mtDNA tree is just a single gene tree, it offers important additional information on the evolutionary history of the Papionini. Future investigations should incorporate a large number of nDNA loci or even complete genome data to possibly distinguish introgression or incomplete lineage sorting. Furthermore, for a reliable comparative study of mtDNA and nDNA sequences data, respective loci are at best obtained from the same individuals or at least the same species. In addition to nDNA data future studies should also include comprehensive sequence data of the herein unstudied genus Rungwecebus. There is also a need to further elucidate intra-generic taxonomy and phylogeny in almost all papionin genera, particularly in Cercocebus. Therefore special attention must be paid to the geographic provenance of studied samples.

\section{Methods}

\section{Sample collection}

Blood samples from one individual each of $M$. arctoides (M. arctoides group), M. silenus (M. silenus group), $M$. tonkeana (Sulawesi group), $M$. fascicularis (M. fascicularis group) and M. sylvanus (M. sylvanus group), and two individuals of $M$. mulatta (M. mulatta group) were obtained from European zoos, Covance Inc., Münster, Germany and the German Primate Center. All blood samples were taken during routine health checks by experienced veterinarians and not specifically for this study. A fresh tissue sample from a deceased $M$. thibetana (M. sinica group) individual was obtained from the Strasbourg Primate Center. Sample collection was approved by the Animal Welfare Body of the German Primate Center and adhered to the American Society of Primatologists Principles for the Ethical Treatment of Non-Human 
Primates (see www.asp.org/society/resolutions/Ethical TreatmentOfNonHumanPrimates.cfm). No animals were sacrificed for this study.

\section{Laboratory methods}

Genomic DNA from blood and tissue samples was extracted using the Qiagen DNeasy Blood \& Tissue Kit following the supplier's recommendations. To minimize the chance of amplifying nuclear mitochondrial-like sequences (numts) [86], two overlapping long-range PCR fragments were generated $(8 \mathrm{~kb}$ and $10 \mathrm{~kb})$ using primers specifically designed for macaque species groups on the basis of available sequence data in GenBank and the Long Range dNTPack from Roche. Conditions for the longrange PCR amplification comprised a pre-denaturation step at $94^{\circ} \mathrm{C}$ for $2 \mathrm{~min}$, followed by 40 cycles at $94^{\circ} \mathrm{C}$ for $1 \mathrm{~min}$, annealing at $60^{\circ} \mathrm{C}$ for $1 \mathrm{~min}$ and extension at $68^{\circ} \mathrm{C}$ for $20 \mathrm{~min}$. At the end a final extension step at $68^{\circ} \mathrm{C}$ for 30 min was added. PCR products were visualized on $1 \%$ agarose gel and extracted with the Qiagen PCR purification Kit. Obtained long-range fragments were used as template for nested PCRs to generate products of 1.0 to $1.2 \mathrm{~kb}$. Respective primers are available from the authors upon request. PCR conditions for nested PCRs comprised a pre-denaturation step at $94^{\circ} \mathrm{C}$ for $2 \mathrm{~min}$, followed by 40 cycles each with denaturation at $94^{\circ} \mathrm{C}$ for $1 \mathrm{~min}$, annealing at $60^{\circ} \mathrm{C}$ for $1 \mathrm{~min}$ and extension at $72^{\circ} \mathrm{C}$ for $1.5 \mathrm{~min}$, and terminating with a final extension step at $72^{\circ} \mathrm{C}$ for $5 \mathrm{~min}$. PCR products were again checked on $1 \%$ agarose gels, and subsequently extracted and sequenced on an ABI 3130xL sequencer using the BigDye Terminator Cycle Sequencing Kit (Applied Biosystems) and the amplification primers. DNA extraction, PCR set-up, gel extraction and sequencing were performed in separate laboratories. Genome sequences were assembled with SeaView 4.4.0. [87] and annotation was conducted with the online program DOGMA [88] and manually checked. Sequences in the overlapping parts of the two long-range PCRs were identical and all protein-coding genes were correctly translated without any premature stop codons, indicating that no numt contamination is present in our data. All sequences were deposited at GenBank (for accession numbers see Additional file 7: Table S2).

\section{Data analysis}

The dataset for the phylogenetic analysis comprised a total of $38 \mathrm{mtDNA}$ genome sequences including 13 macaques representing all seven species groups ( $2 M$. sylvanus, $1 M$. silenus, $1 \mathrm{M}$. tonkeana, $2 \mathrm{M}$. thibetana, $3 \mathrm{M}$. mulatta, $3 \mathrm{M}$. fascicularis and $1 M$. arctoides), eleven baboons (2 P. ursinus, 2 P. hamadryas, 3 P. anubis, 2 P. cynocephalus, $1 P$. kindae and $1 P$. papio), three geladas (T. gelada), one drill (M. leucophaeus), one mandrill (M. sphinx), one crested mangabey (L. aterrimus), three capped mangabeys (1 C. chrysogaster, 1 C. atys, 1 C. torquatus) and five nonpapionin primate species (Chlorocebus pygerythrus, Colobus guereza, Pongo abelii, Pan troglodytes, Homo sapiens). Accordingly, Rungwecebus was the only missing papionin genus. The identity of the $C$. torquatus individual remained ambiguous. While it was originally assigned to Lophocebus albigena [78], BLAST-search revealed that it is $99-100 \%$ identical to available mtDNA sequences of $C$. torquatus. For information about GenBank accession numbers and the source of the herein used sequences see Additional file 7: Table S2.

Sequences were aligned with Muscle 3.7 [89] as implemented in SeaView and manually corrected. For phylogenetic tree reconstructions, indels and poorly aligned positions were removed with Gblocks 0.91b [90]. To check for possible shifts in base composition among species, we calculated the base composition for each species using PAUP 4.0b10 [91]. Since we observed a slight shift in $\mathrm{A} / \mathrm{C}$ content among papionins (Additional file 3: Figure S1) and to test whether this shift might have influenced phylogenetic inferences, we generated a second alignment (dataset 2) in which positions that contained both an Adenin and Cytosin were masked with an "M" (in total 606 positions).

The programs RAxML 0.93 [92] and MrBayes 3.1.2 $[93,94]$ were used for phylogenetic tree reconstructions applying ML and Bayesian algorithms. As substitution models for Bayesian reconstructions we applied the $\operatorname{TrN}+$ $\mathrm{I}+\mathrm{G}$ and $\mathrm{GTR}+\mathrm{I}+\mathrm{G}$ models for datasets 1 and 2 , respectively, as they were selected as best-fit models by jModeltest 2.1 [95] under the Bayesian information criterion (BIC) and the Decision Theory Performance-based Selection (DT). In MrBayes we analysed four independent Markov Chain Monte Carlo (MCMC) runs with a default temperature of 0.2 . All repetitions were run for 1 million generations with tree and parameter sampling setting in every 100 generations. The first $25 \%$ of samples were discarded as burn-in, resulting in 75,001 trees per run. The adequacy of the burn-in and convergence of all parameters was assessed via the uncorrected potential scale reduction factor (PSRF) [96] as calculated by MrBayes and by visual inspection of the trace of the parameters across generations using the software TRACER 1.5 [97]. To check whether posterior clade probabilities were also converging, AWTY [98] was used. Posterior probabilities for each split and a phylogram with mean branch lengths were calculated from the posterior density of trees. Both ML calculations in RAxML were run with the CAT-GTR model and 1,000 rapid bootstrapping replications. Alternative phylogenetic relationships among the three observed major papionin clades were tested with the Kishino-Hasegawa test [99] and Shimodaira-Hasegawa test [100] with full optimisation and 1,000 bootstrap replications in PAUP. 
Divergence ages were estimated applying both, uncorrelated and autocorrelated, clock models. To calculate divergence ages with an uncorrelated clock model, we used BEAST 1.6.1 [101,102]. We assumed a relaxed lognormal model of lineage variation and a Birth-Death Process prior for branching rates. In contrast to Finstermeier et al. [19], branching of Mandrillus + Cercocebus with Macaca was not constrained in our study as alternative branching patterns were rejected by alternative tree topology tests.

The following five fossil-based calibration points were applied with a normal distribution prior for respective nodes: The Homo - Pan split $6.5 \mathrm{Ma}$ with a 95\% credibility interval (CI) of $0.5 \mathrm{Ma}$ [103-105]. The split between Pongo and the Homo-Pan lineage at $14.0 \mathrm{Ma}$ (95\% CI: $1.0 \mathrm{Ma}$ [ [106], the divergence of Theropithecus and Papio $5.0 \mathrm{Ma}$ (95\% CI: $1.5 \mathrm{Ma})[107,108]$, the split between African and Asian macaques at 5.5 Ma (95\% CI: $1.0 \mathrm{Ma}$ ) $[27,108]$ and the separation of hominoids and cercopithecoids at 27.5 Ma (95\% CI: 3.5 Ma) [109-111].

In total, we ran four replicates in BEAST, each with 25 million generations, and tree and parameter sampling every 1,000 generations. TRACER was applied to assess the adequacy of a $10 \%$ burn-in and the convergence. The sampling distributions were combined (25\% burnin) with LogCombiner 1.6.1 and a consensus chronogram with node height distribution was generated and visualized with TreeAnnotator 1.6.1 and FigTree 1.4.0 [112].

To see whether the application of an autocorrelated model instead of an uncorrelated model has an effect on the divergence time estimation we performed Bayesian molecular dating with the software package PhyloBayes 3.3 [113]. The tree topology was fixed using the topology as inferred from MrBayes. Five node ages were fixed by specifying calibration intervals based on the same calibration points and credibility intervals as mention above. In the main program of PhyloBayes (pb) the CAT-GTR model was applied in combination with a log-normal auto-correlated $(-\ln )$ [114] relaxed clock model and in a second independent run with an uncorrelated (-ugam) [101] relaxed clock model. We monitored the development of the log-likelihood as a function of time and found it to be stable (to show convergence) after approximately 3000-4000 cycles. Hence, 10,000 cycles were carried out discarding the first 2,500 trees as burnin. A posterior consensus chronogram was calculated on the remaining 7,500 trees using the post analysis program readpb and was visualized with FigTree.

\section{Availability of supporting data}

The data set supporting the results of this article is available in the Data Dryad repository, DOI: 10.5061/ dryad.9tm 42 .

\section{Additional files}

\section{Additional file 1: Original alignment of complete mitochondrial} genomes from 38 catarrhine primate taxa.

Additional file 2: Table S1. Divergence ages among catarrhine primates in Ma (95\% credibility intervals) estimated with uncorrelated and autocorrelated relaxed clock models.

Additional file 3: Figure S1. Nucleotide composition among Papionini and outroup taxa.

Additional file 4: Figure S2. Ultrametric tree of Papionini and outgroup taxa as inferred from dataset 2. Tree topologies as inferred from Bayesian (MrBayes) as well as from ML (RAxML) estimations were mainly identical with some exceptions. All unlabelled branches show ML BP of $100 \%$ and Bayesian PP of 1.0. Values below are indicated at respective nodes. Taxa indicated with ${ }^{a}$ are arranged differently in the $M L$ (RAxML) and Bayesian tree (MrBayes): ((P. anubis west2, P. anubis west1) P. papio); ((C. torquatus, C. atys), ((C. chrysogaster, M. leucophaeus), $M$. sphinx)). Red ellipse indicates main difference to Figure $1 .{ }^{*}=$ sequences were newly generated in this study.

Additional file 5: Figure S3. Tree topology including divergence dates as estimated with an auto-correlated relaxed clock model as implemented in PhyloBayes 3.3. Time scale shows million years before present. * = sequences were newly generated in this study.

Additional file 6: Figure S4. Tree topology including divergence dates as estimated with an uncorrelated relaxed clock model as implemented in PhyloBayes 3.3. Time scale shows million years before present.

* = sequences were newly generated in this study.

Additional file 7: Table S2. Studied species and individuals along with their GenBank accession numbers.

\section{Competing interests}

The authors declare that they have no competing interests.

\section{Authors' contributions}

$\mathrm{RL}$ did laboratory work, analysed data, and wrote the paper. MB analysed data. DZ and CR designed the study, analysed data, and wrote the paper. All authors read and approved the final manuscript.

\section{Acknowledgements}

We thank the zoos in Dresden, Madrid, Salem, Straubing and Wuppertal as well as Covance Inc. (Münster, Gemany), the Strasbourg Primate Center and the German Primate Center for providing valuable macaque samples. We are also grateful to Christiane Schwarz for her excellent laboratory work, and Colin Groves and Brandon C. Wheeler for their valuable comments on an earlier version of the paper and their corrections of the English. We thank the editor and three anonymous reviewers for critical comments on an earlier version of the manuscript.

\section{Author details}

${ }^{1}$ Primate Genetics Laboratory, German Primate Center, Leibniz Institute for Primate Research, Kellnerweg 4, 37077 Göttingen, Germany. ${ }^{2}$ Gene Bank of Primates, German Primate Center, Leibniz Institute for Primate Research, Kellnerweg 4, 37077 Göttingen, Germany. ${ }^{3}$ Cognitive Ethology Laboratory, German Primate Center, Leibniz Institute for Primate Research, Kellnerweg 4, 37077 Göttingen, Germany.

Received: 5 March 2014 Accepted: 25 July 2014

Published online: 04 September 2014

\section{References}

1. Moore WS: Inferring phylogenies from mtDNA variation: mitochondrial-gene trees versus nuclear-gene trees. Evolution 1995, 49:718-726.

2. Hoelzer GA: Inferring phylogenies from mtDNA variation: Mitochondrial-gene trees versus nuclear-gene trees revisited. Evolution 1997, 51:622-626.

3. Avise JC: Molecular Markers, Natural History, and Evolution. Sunderland, MA: Sinauer Associates; 2004.

4. Maddison WP: Gene trees in species trees. Syst Biol 1997, 46:523-536. 
5. Funk DJ, Omland KE: Species-level paraphyly and polyphyly: frequency, causes, and consequences, with insights from animal mitochondrial DNA. Ann Rev Ecol Evol Syst 2003, 34:397-423.

6. Avise JC: Phylogeography: retrospect and prospect. J Biogeograph 2009, 36:3-15.

7. Tosi AJ, Morales JC, Melnick DJ: Y-chromosome and mitochondrial markers in Macaca fascicularis indicate introgression with Indochinese $M$. mulatta and a biogeographic barrier in the Isthmus of Kra. Int J Primatol 2002, 23:161-178.

8. Storz JF, Ramakrishnan U, Alberts SC: Genetic effective size of a wild primate population: influence of current and historical demography. Evolution 2002, 56:817-829.

9. Roberts TE, Davenport TRB, Hildebrandt KBP, Jones T, Stanley WT, Sargis EJ, Olson LE: The biogeography of introgression in the critically endangered African monkey Rungwecebus kipunji. Biol Lett 2010, 6:233-237.

10. Zinner D, Arnold ML, Roos C: Is the new primate genus Rungwecebus a baboon? PLoS One 2009, 4:e4859.

11. Zinner D, Groeneveld LF, Keller C, Roos C: Mitochondrial phylogeography of baboons (Papio spp.) - Indication for introgressive hybridization? BMC Evol Biol 2009, 9:83.

12. Zinner D, Arnold ML, Roos C: The strange blood: natural hybridization in primates. Evol Anthropol 2011, 20:96-103.

13. Satkoski Trask JA, Garnica WT, Smith DG, Houghton P, Lerche N, Kanthaswamy S: Single-Nucleotide Polymorphisms reveal patterns of allele sharing across the species boundary between rhesus (Macaca mulatta) and cynomolgus (M. fascicularis) macaques. Am J Primatol 2013, 75:135-144.

14. Guevara EE, Steiper ME: Molecular phylogenetic analysis of the Papionina using concatenation and species tree methods. J Human Evol 2014, 66:18-28.

15. Perelman $P$, Johnson WE, Roos C, Seuánez HN, Horvath JE, Moreira MAM, Kessing B, Pontius J, Roelke M, Rumpler Y, Schneider MPC, Silva A, O'Brien SJ, Pecon-Slattery J: A molecular phylogeny of living primates. PLoS Genet 2011, 7:e1001342.

16. Zinner D, Fickenscher G, Roos C: Family Cercopithecidae (Old World Monkeys). In The Handbook of the Mammals of the World, Primates, Volume 3. Edited by Mittermeier RA, Rylands AB, Wilson DE. Barcelona: Lynx Edicions; 2013:550-627.

17. Page SL, Goodman M: Catarrhine phylogeny: noncoding DNA evidence for a diphyletic origin of the mangabeys and for a human-chimpanzee clade. Mol Phylogenet Evol 2001, 18:14-25.

18. Xing J, Wang H, Han K, Ray DA, Huang CH, Chemnick LG, Stewart CB, Disotell TR, Ryder OA, Batzer MA: A mobile element based phylogeny of Old World monkeys. Mol Phylogenet Evol 2005, 37:872-880

19. Finstermeier K, Zinner D, Brameier M, Meyer M, Kreuz E, Hofreiter M, Roos C: A mitogenomic phylogeny of living primates. PLOS One 2013, 8:e69504.

20. Pozzi L, Hodgson JA, Burrell AS, Sterner KN, Raaum RL, Disotell TR: Primate phylogenetic relationships and divergence dates inferred from complete mitochondrial genomes. Mol Phylogenet Evol 2014, 75:165-183.

21. Delson E: Evolutionary history of the Cercopithecidae. Contrib Primatol 1975, 5:167-217

22. Stewart CB, Disotell TR: Primate evolution - in and out of Africa. Curr Biol 1998, 8:R582-R588.

23. Groves CP: Primate Taxonomy. Washington, DC: Smithsonian Institution Press; 2001.

24. Böhm M, Mayhew P: Historical biogeography and the evolution of the latitudinal gradient of species richness in the Papionini (Primata: Cercopithecidae). Biol J Linnean Soc 2005, 85:235-246.

25. Jolly CJ: Tribe Papionini. In Mammals of Africa, Primates, Volume II. Edited by Butynski TM, Kingdon J, Kalina J. London: Bloomsbury Publishing; 2013:157-158.

26. Delson E: Fossil macaques, phyletic relationships and a scenario of deployment. In The Macaques: Studies in Ecology, Behavior and Evolution. Edited by Lindhurg D. New York: Van Nostrand Reinhold; 1980:10-30.

27. Alba DM, Delson E, Carnevale G, Colombero S, Delfino M, Giuntelli P, Pavia M, Pavia G: First joint record of Mesopithecus and cf. Macaca in the Miocene of Europe. J Hum Evol 2014, 67:1-18.

28. Gupta VJ, Sahni A: Theropithecus delsoni, a new cercopithecine species from the Upper Siwaliks of India. Bull Ind Geol Ass 1981, 14:69-71.

29. Delson E: Theropithecus fossils from Africa and India and the taxonomy of the genus. In Theropithecus: The Rise and Fall of a Primate Genus.
Edited by Jablonski NG. Cambridge: Cambridge University Press; 1993:157-189.

30. Delson E, Eck GG, Leakey MG, Jablonski NG: A partial catalogue of fossil remains of Theropithecus. In Theropithecus: The Rise and Fall of a Primate Genus. Edited by Jablonski NG. Cambridge: Cambridge University Press; 1993:499-525.

31. Pickford M: Climatic change, biogeography, and Theropithecus. In Theropithecus: The Rise and Fall of a Primate Genus. Edited by Jablonsk NG. Cambridge: Cambridge University Press; 1993:227-243.

32. Gibert J, Ribot F, Gibert L, Leakey M, Arribas A, Martinez B: Presence of the cercopithecid genus Theropithecus in Cueva Victoria (Murcia, Spain). J Hum Evol 1995, 28:487-493.

33. Rook L, Martínez-Navarro B, Clark Howell F: Occurrence of Theropithecus $\mathrm{sp}$. in the Late Villafranchian of Southern Italy and implication for Early Pleistocene "out of Africa" dispersals. J Hum Evol 2004, 47:267-277.

34. Roberts P, Delson E, Miracle P, Ditchfield P, Roberts RG, Jacobs Z, Blinkhorn J, Ciochon RL, Fleagle JG, Frost SR, Gilbert CC, Gunnell GF, Harrison T, Korisettar R, Petraglia MD: Continuity of mammalian fauna over the last 200,000 y in the Indian subcontinent. Proc Natl Acad Sci U S A 2014, 111(16):5848-5853.

35. Fooden J: Provisional classification and key to living species of macaques (Primates: Macaca). Folia Primatol 1976, 25:225-236.

36. Anandam MV, Bennett EL, Davenport TRB, Davies NJ, Detwiler KM, Engelhardt A, Eudey AA, Gadsby EL, Groves CP, Healy A, Karanth KP, Molur S, Nadler T, Richardson MC, Riley EP, Roos C, Rylands AB, Sheeran LK, Ting N, Wallis J, Waters SS, Whittaker DJ, Zinner D: Species accounts of Cercopithecidae. In The Handbook of the Mammals of the World, Primates, Volume 3. Edited by Mittermeier RA, Rylands AB, Wilson DE. Barcelona: Lynx Edicions; 2013:628-753.

37. Tosi AJ, Morales JC, Melnick DJ: Paternal, maternal, and biparental molecular markers provide unique windows onto the evolutionary history of macaque monkeys. Evolution 2003, 57:1419-1435.

38. Ziegler T, Abegg C, Meijaard E, Perwitasari-Farajallah D, Walter L, Hodges JK, Roos C: Molecular phylogeny and evolutionary history of Southeast Asian macaques forming the M. silenus group. Mol Phylogenet Evol 2007, 42:807-816

39. Hayasaka K, Fujii K, Horai S: Molecular phylogeny of macaques: implications of nucleotide sequences from an 896 base pair region of mitochondrial DNA. Mol Biol Evol 1996, 13:1044-1053.

40. Morales JC, Melnick DJ: Phylogenetic relationships of the macaques (Cercopithecidae: Macaca), as revealed by high resolution restriction site mapping of mitochondrial ribosomal genes. J Hum Evol 1998, 34:1-23.

41. Disotell TR, Honeycutt RL, Ruvolo M: Mitochondrial DNA phylogeny of the Old-World monkey tribe Papionini. Mol Biol Evol 1992, 9:1-13.

42. Szalay FS, Delson E: Evolutionary History of the Primates. New York: Academic; 1979

43. Strasser E, Delson E: Cladistic analysis of cercopithecid relationships. J Hum Evol 1987, 16:81-99.

44. Groves CP: Phylogenetic and population systematics of the mangabeys (Primates: Cercopithecoidea). Primates 1978, 19:1-34.

45. Fleagle JG, McGraw WS: Skeletal and dental morphology supports diphyletic origin of baboons and mandrills. Proc Natl Acad Sci U S A 1999, 96:1157-1161

46. Gilbert CC: Craniomandibular morphology supporting the diphyletic origin of mangabeys and a new genus of the Cercocebus/Mandrillus clade, Procercocebus. J Hum Evol 2007, 53:69-102.

47. Harris EE, Disotell TR: Nuclear gene trees and the phylogenetic relationships of the mangabeys (Primates: Papionini). Mol Biol Evol 1998, 15:892-900.

48. Harris EE: Molecular systematics of the Old World monkey tribe Papionini: analysis of the total available genetic sequences. $J$ Hum Evol 2000, 38:235-256.

49. Jones T, Ehardt CL, Butynski TM, Davenport TRB, Mpunga NE, Machaga SJ, De Luca DW: The highland mangabey Lophocebus kipunji: a new species of African monkey. Science 2005, 308:1161-1164.

50. Davenport TRB, Stanley WT, Sargis EJ, De Luca DW, Mpunga NE, Machaga SJ, Olson LE: A new genus of African monkey, Rungwecebus: morphology, ecology, and molecular phylogenetics. Science 2006, 312:1378-1381.

51. Burrell AS, Jolly CJ, Tosi AJ, Disotell TR: Mitochondrial evidence for the hybrid origin of the kipunji, Rungwecebus kipunji (Primates: Papionini). Mol Phylogenet Evol 2009, 51:340-348. 
52. Newman TK, Jolly CJ, Rogers J: Mitochondrial phylogeny and systematics of baboons (Papio). Am J Phys Anthropol 2004, 124:17-27.

53. Wildman DE, Bergman TJ, al-Aghbari A, Sterner KN, Newman TK, Phillips-Conroy JE, Jolly CJ, Disotell TR: Mitochondrial evidence for the origin of hamadryas baboons. Mol Phylogenet Evol 2004, 32:287-296.

54. Zinner D, Wertheimer J, Liedigk R, Groeneveld LF, Roos C: Baboon phylogeny as inferred from complete mitochondrial genomes. Am J Phys Anthropol 2013, 150:133-140.

55. Fleagle JG, McGraw WS: Skeletal and dental morphology of African papionins: unmasking a cryptic clade. J Hum Evol 2002, 42:267-292.

56. Chatterjee HJ, Ho SYW, Barnes I, Groves C: Estimating the phylogeny and divergence times of primates using a supermatrix approach. BMC Evol Biol 2009, 9:259

57. Chan YC, Roos C, Inoue-Murayama M, Inoue E, Shih CC, Pei KJC, Vigilant L: Mitochondrial genome sequences effectively reveal the phylogeny of Hylobates gibbons. PLoS One 2010, 5:e14419.

58. Chiou KL, Pozzi L, Lynch Alfaro JW, Di Fiore A: Pleistocene diversification of living squirrel monkeys (Saimiri spp.) inferred from complete mitochondrial genome sequences. Mol Phylogenet Evol 2011, 59:736-745

59. Roos C, Zinner D, Kubatko L, Schwarz C, Yang M, Meyer D, Nash S, Xing J, Batzer MA, Brameier M, Leendertz FH, Ziegler T, Perwitasari-Farjajjah D, Nadler T, Walter L, Osterholz M: Nuclear versus mitochondrial DNA: evidence for hybridization in colobine monkeys. BMC Evol Biol 2011, 11:77.

60. Liedigk R, Yang M, Jablonski NG, Momberg F, Geissmann T, Lwin N, Hla TH, Liu Z, Wong B, Ming L, Yongcheng L, Zhang YP, Nadler T, Zinner D, Roos C: Evolutionary history of the odd-nosed monkeys and the phylogenetic position of the newly described Myanmar snub-nosed monkey Rhinopithecus strykeri. PLoS One 2012, 7:e37418.

61. Supplementary data from: Mitogenomics of the Old World monkey tribe Papionini. Dryad Digital Repository. [http://doi:10.5061/dryad.9tm42]

62. Bouckaert RR: DensiTree: making sense of sets of phylogenetic trees. Bioinformatics 2010, 26:1372e1373.

63. Pollard DA, lyer VN, Moses AM, Eisen MB: Widespread discordance of gene trees with species tree in Drosophila: evidence for incomplete lineage sorting. PLOS Genet 2006, 2:e173.

64. Raaum RL, Sterner KN, Noviello CM, Stewart CB, Disotell TR: Catarrhine primate divergence dates estimated from complete mitochondrial genomes: concordance with fossil and nuclear DNA evidence. J Hum Evol 2005, 48:237-257.

65. Steiper ME, Young NM: Primate molecular divergence dates. Mol Phylogenet Evol 2006, 41:384-394

66. Li J, Han K, Xing J, Kim HS, Rogers J, Ryder OA, Disotell T, Yue B, Batzer MA: Phylogeny of macaques (Cercopithecidae: Macaca) based on Alu elements. Gene 2009, 448:242-249.

67. Pollock DD, Zwickl DJ, Mcguire JA, Hillis DM: Increased taxon sampling is advantageous for phylogenetic inference. Syst Biol 2002, 51:664-671.

68. Zwickl DJ, Hillis DM: Increased taxon sampling greatly reduces phylogenetic error. Syst Biol 2002, 51:588-598.

69. Townsend JP, Leuenberger C: Taxon sampling and the optimal rates of evolution for phylogenetic inference. Syst Biol 2011, 60:358-365.

70. Nabhan $A R$, Sarkar IN: The impact of taxon sampling on phylogenetic inference: a review of two decades of controversy. Brief Bioinform 2012, 13:122-134.

71. Springer MS, Meredith RW, Gatesy J, Emerling CA, Park J, Rabosky DL, Stadler T, Steiner C, Ryder OA, Janecka JE, Fisher CA, Murphy WJ: Macroevolutionary dynamics and historical biogeography of primate diversification inferred from a species supermatrix. PLoS One 2012, 7:e49521.

72. McGraw WS, Fleagle JG: Biogeography and evolution of the Cercocebus- Mandrillus clade: evidence from the face. In Primate Biogeography: Progress and Prospects. Edited by Lehman SM, Fleagle JG. New York: Springer; 2006:201-224

73. Ito T, Nishimura T, Takai M: Ecogeographical and phylogenetic effects on craniofacial variation in macaques. Am J Phys Anthropol 2014, 154:27-41.

74. Maddison WP, Knowles LL: Inferring phylogeny despite incomplete lineage sorting. Syst Biol 2006, 55:21-30.

75. Keller C, Roos C, Groeneveld LF, Fischer J, Zinner D: Introgressive hybridization in southern African baboons shapes patterns of mtDNA variation. Am J Phys Anthropol 2010, 142:125-136.

76. Arnold ML, Meyer A: Natural hybridization in primates: one evolutionary mechanism. Zoology 2006, 109:261-276.
77. Chiarelli B: Check-list of catarrhina primate hybrids. J Hum Evol 1973, 2:301-305.

78. Guschanski K, Krause J, Sawyer S, Valente LM, Bailey S, Finstermeier K, Sabin R, Gilissen E, Sonet G, Nagy ZT, Lenglet G, Mayer F, Savolainen V: Next-generation museomics disentangles one of the largest primate radiations. Syst Biol 2013, 62:539-554.

79. Kingdon J: The Kingdon Field Guide to African Mammals. London: Academic; 1997.

80. Gilbert CC, Rossie JB: Congruence of molecules and morphology using a narrow allometric approach. Proc Natl Acad Sci U S A 2007, 104:11910-11914.

81. Gilbert CC: African papionin phylogenetic history and Plio-Pleistocene biogeography, PhD thesis. Stony Brook University; 2008.

82. Gilbert CC: Cladistic analysis of extant and fossil African papionins using craniodental data. J Hum Evol 2013, 64:399-433.

83. Fooden J: Classification and distribution of living macaques. In The Macaques: Studies in Ecology, Behavior, and Evolution. Edited by Lindburg DG. New York: Van Nostrand-Reinhold; 1980:1-9.

84. Goodman M, Porter CA, Czelusniak J, Page SL, Schneider H, Shoshani J, Gunnell G, Groves CP: Toward a phylogenetic classification of primates based on DNA evidence complemented by fossil evidence. Mol Phylogenet Evol 1998, 9:585-598.

85. Groves CP: The what, why and how of primate taxonomy. Int I Primatol 2004, 25:1105-1126

86. Thalmann O, Hebler J, Poinar HN, Pääbo S, Vigilant L: Unreliable mtDNA data due to nuclear insertions: a cautionary tale from analysis of humans and other great apes. Mol Ecol 2004, 13:321-325.

87. Gouy M, Guindon S, Gascuel O: SeaView version 4: a multiplatform graphical user interface for sequence alignment and phylogenetic tree building. Mol Biol Evol 2010, 27:221-224.

88. Wyman SK, Jansen RK, Boore JL: Automatic annotation of organellar genomes with DOGMA. Bioinformatics 2004, 20:3252-3255.

89. Edgar RC: MUSCLE: multiple sequence alignment with high accuracy and high throughput. Nucleic Acids Res 2004, 32:1792-1797.

90. Castresana J: Selection of conserved blocks from multiple alignments for their use in phylogenetic analysis. Mol Biol Evol 2000, 17:540-552.

91. Swofford DL: PAUP* Phylogenetic Analysis using Parsimony ( ${ }^{*}$ and other Methods), Version 4. Sunderland: Sinauer Associates; 2003.

92. Stamatakis A: RAxML-VI-HPC: maximum likelihood-based phylogenetic analyses with thousands of taxa and mixed models. Bioinformatics 2006, 22:2688-2690.

93. Huelsenbeck JP, Ronquist F, Nielsen R, Bollback JP: Bayesian inference of phylogeny and its impact on evolutionary biology. Science 2001, 294:2310-2314.

94. Ronquist F, Huelsenbeck JP: MrBayes 3: Bayesian phylogenetic inference under mixed models. Bioinformatics 2003, 19:1572-1574.

95. Posada D: Selection of models of DNA evolution with jModelTest. Methods Mol Biol 2009, 537:93-112.

96. Gelman A, Rubin D: Inference from iterative simulation using multiple sequences. Stat Sci 1992, 7:457-511.

97. Rambaut A, Drummond AJ: Tracer: MCMC trace analysis tool, version 1.5 http://tree.bio.ed.ac.uk/software/tracer/.

98. Nylander JA, Wilgenbusch JC, Warren DL, Swofford DL: AWTY (are we there yet?): a system for graphical exploration of MCMC convergence in Bayesian phylogenetics. Bioinformatics 2008, 24:581-583.

99. Kishino $H$, Hasegawa M: Evaluation of the maximum likelihood estimate of the evolutionary tree topologies from DNA sequence data, and their branching order of Hominoidea. J Mol Evol 1989, 29:170-179.

100. Shimodaira H, Hasegawa M: Multiple comparisons of log likelihoods with applications to phylogenetic inference. Mol Biol Evol 1999, 16:1114-1116.

101. Drummond AJ, Ho SY, Phillips MJ, Rambaut A: Relaxed phylogenetics and dating with confidence. PLOS Bio/ 2006, 4:e88

102. Drummond AJ, Rambaut A: BEAST: Bayesian evolutionary analysis by sampling trees. BMC Evol Biol 2007, 7:214

103. Vignaud $P$, Duringer $P$, Mackaye HT, Likius A, Blondel C, Boisserie JR, De Bonis L, Eisenmann V, Etienne ME, Geraads D, Guy F, Lehmann T, Lihoreau F, Lopez-Martinez N, Mourer-Chauvire C, Otero O, Rage JC, Schuster M, Viriot L, Zazzo A, Brunet M: Geology and palaeontology of the upper Miocene Toros-Menalla hominid locality, Chad. Nature 2002, 418:152-155.

104. Brunet M, Guy F, Pilbeam D, Lieberman DE, Likius A, Mackaye HT, Ponce de León MS, Zollikofer CP, Vignaud P: New material of the earliest hominid from the upper Miocene of Chad. Nature 2005, 434:752-755. 
105. Lebatard AE, Bourles DL, Duringer P, Jolivet M, Braucher R, Carcaillet J, Schuster M, Arnaud N, Monie P, Lihoreau F, Likius A, Mackaye HT, Vignaud $\mathrm{P}$, Brunet M: Cosmogenic nuclide dating of Sahelanthropus tchadensis and Australopithecus bahrelghazali: Mio-Pliocene hominids from Chad. Proc Natl Acad Sci U S A 2008, 105:3226-3323.

106. Kelley J: The hominoid radiation in Asia. In The Primate Fossil Record. Edited by Hartwig WC. Cambridge: Cambridge University Press; 2002:369-384

107. Leakey MG: Evolution of Theropithecus in the Turkana Basin. In Theropithecus: The Rise and Fall of a Primate Genus. Edited by Jablonski NG. Cambridge: Cambridge University Press; 1993:85-123.

108. Delson E: Cercopithecinae. In Encyclopedia of Human Evolution and Prehistory. Edited by Delson E, Tattersall I, Van Couvering JA, Brooks AS New York: Garland Publishing Inc; 2000:166-171.

109. Zalmout IS, Sanders WJ, MacLatchy LM, Gunnell GF, Al-Mufarreh YA, Ali MA, Nasser AAH, Al-Masari AM, Al-Sobhi SA, Nadhra AO, Matari AH, Wilson JA, Gingerich PD: New Oligocene primate from Saudi Arabia and the divergence of apes and Old World monkeys. Nature 2010, 466:360-365.

110. Pozzi L, Hodgson JA, Burrell AS, Disotell TR: The stem catarrhine Saadanius does not inform the timing of the origin of crown catarrhines. J Hum Evol 2011, 61:209-210

111. Stevens NJ, Seiffert ER, O'Connor PM, Roberts EM, Schmitz MD, Krause C, Gorscak E, Ngasala S, Hieronymus TL, Temu J: Palaeontological evidence for an Oligocene divergence between Old World monkeys and apes. Nature 2013, 497:611-614.

112. Rambaut A: FigTree: tree figure drawing tool, version 1.4.0. http://tree.bio.ed. ac.uk/software/figtree/.

113. Lartillot N, Lepage T, Blanquart S: PhyloBayes 3: a Bayesian software package for phylogenetic reconstruction and molecular dating. Bioinformatics 2009, 25:2286-2288.

114. Thorne JL, Kishino H, Painter IS: Estimating the rate of evolution of the rate of molecular evolution. Mol Biol Evol 1998, 15:1647-1657.

doi:10.1186/s12862-014-0176-

Cite this article as: Liedigk et al: Mitogenomics of the Old World

monkey tribe Papionini. BMC Evolutionary Biology 2014 14:176.

\section{Submit your next manuscript to BioMed Central and take full advantage of:}

- Convenient online submission

- Thorough peer review

- No space constraints or color figure charges

- Immediate publication on acceptance

- Inclusion in PubMed, CAS, Scopus and Google Scholar

- Research which is freely available for redistribution 